\section{New radiation safety guidance launched}

The British Institute of Radiology (BIR) has produced posters, videos and a book on personal protective equipment (PPE) for staff working with radiation, to help reduce exposure to diagnostic X-rays and develop radiation safety knowledge in and beyond the radiology department. The guidance gives practical advice on how staff should select, wear and store their PPE. Importantly it gives clear advice on how to comply with regulations, and prepare a risk assessment.

It is crucial that protective aprons, head and eye wear are worn and fitted correctly to protect the body against dangerous radiation levels. If stored incorrectly, the equipment can become damaged and that immediately reduces its effectiveness.

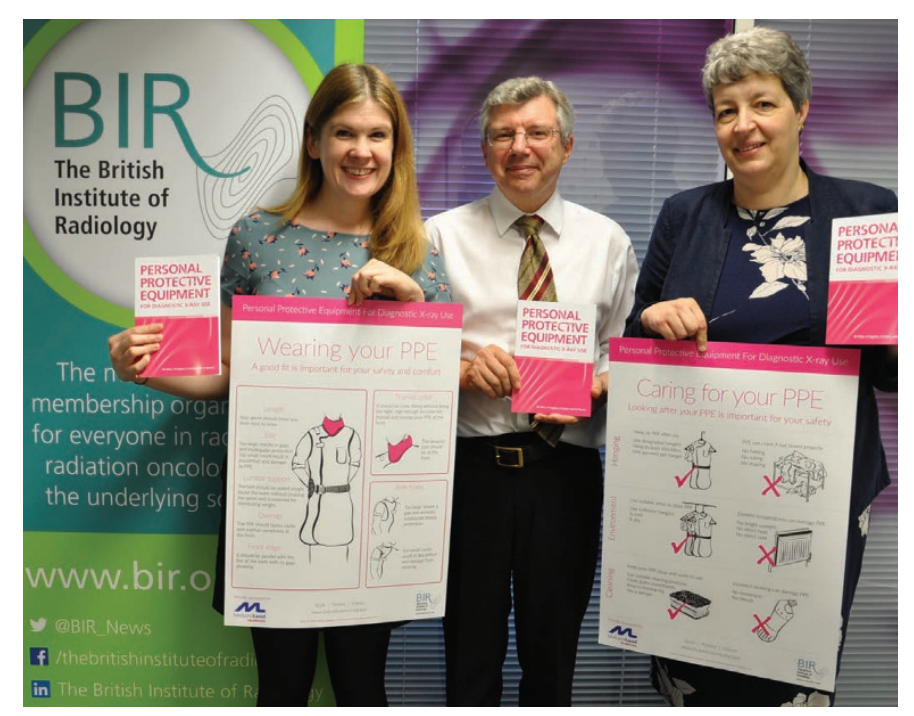

The book, Personal protective equipment for diagnostic X-ray use, is a practical guide to using and caring for PPE and is written by Peter A. Hiles, Helen Hughes, Denise Arthur and Colin J. Martin as part of a BIR Working Party with support from the BIR Radiation Safety Special Interest Group (SIG). Products created in conjunction with the book are two A2 sized posters, Caring for your PPE and Wearing your PPE and three videos, Wear and Fit, Care and Storage and Screening PPE.

The resources are for radiologists, trainees, radiographers at all levels, radiology managers, radiation protection advisors (RPAs), medical physicists, vets, dentists, nurses and clinical application specialists.

The book and posters are available to purchase from https:// birorgukportal.force.com/BookList and the videos can be viewed for free on the PPE resources page: http://www.birpublications.org/ppe.

\section{Eastern Counties Branch}

The BDA Eastern Counties Branch Annual General Meeting will be held on Wednesday, 19 October 2016, at Ravenwood Hall, IP30 9JA. 6.00 for $6.30 \mathrm{pm}$. For further information and to confirm your attendance or submit apologies please contact Malcolm Heath, Branch Secretary on mlheath@aol.com.

\section{Elections to the Principal Executive Committee of the British Dental Association}

Nominations are sought for the following seats on the Principal Executive Committee (PEC):

\author{
UK-wide (one seat) \\ Scotland (one seat) \\ England: \\ East Midlands and Central (one seat) \\ Greater London (one seat) \\ South East (one seat)
}

The PEC has overall responsibility for the control and direction of the policy and affairs of the BDA, and its members are the directors of the Association.

There are fifteen members on the PEC. Each will have a share of overall responsibilities, and typically this will require:

- Attendance at all meetings of the PEC - around five a year, but maybe more when business demands

- Attendance at own country council meetings - usually three a year

- Attendance at UK Council meetings - around two a year

- Sit on 1-2 sub committees/issue specific forums

- Attend general meetings of the Association.

It is anticipated that the approximate time commitment for a member of the PEC will be 20 days per year, with an annual remuneration of $£ 15,000$.

\section{Term of office}

This shall be until December 2019, with the opportunity to stand for a further full three-year term of office at that point.

\section{Induction, support and training}

Membership of the PEC carries significant organisational and legal responsibilities. There is an induction programme for those elected, and ongoing training. Members will also have advice and support from the Chief Executive and the wider BDA team.

\section{Next meetings of the PEC}

Meetings of the PEC in 2017 are currently scheduled for: Thursday 9 February, Wednesday 10 May, Wednesday 12 July, Wednesday 27 September, Wednesday 13 December.

Nomination forms must be returned to the Elections Team at 64 Wimpole Street London W1G 8YS or elections@bda.org by 17.00 Friday 4 November 2016.

More information about the elections to the PEC and downloadable nomination forms can be found at: www.bda.org/elections.

Hard copy election packs can also be obtained by contacting Stephen Skelton on 02075634141 or emailing elections@bda.org. 